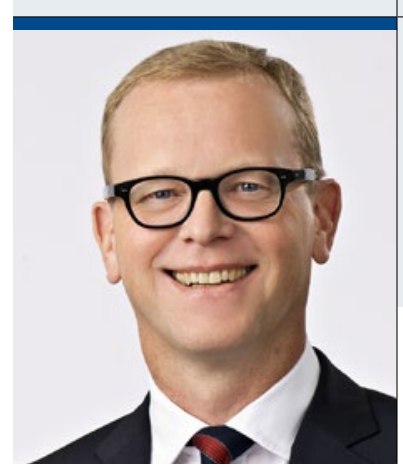

"Dass sich klinisch wie akademisch wissenschaftlich

exzellente Kinderurologen eher niederlassen als einen Lehrstuhl

zu übernehmen, (...) ist bedenklich."

\title{
Kathedralen bauen
}

\section{oder Hütten zimmern?}

A ls Stefan Roth mich in einer Kölner Traditionskneipe bat, auf dem letztjährigen Kongress der Deutschen Gesellschaft für Urologie (DGU) einen Vortrag mit dem Titel „Kinderurologische Erkrankungen: Ist der Kinderurologe besser als der Kinderchirurg?“" (s. „Der wunde Punkt", S. 20) zu halten, war mir in rheinischer Bierseligkeit nicht unmittelbar klar, wie brisant diese aus meiner Sicht natürlich rhetorische Frage ist.

\section{Kirchlein um Kirchlein geht verloren}

Kurz vor der DGU-Tagung hatte ein Kinderchirurg seine Antrittsvorlesung im - leider - ehemaligen Epizentrum der deutschen Kinderurologie - Mainz - bezeichnenderweise „Kathedralen bauen“ betitelt und damit seine himmelsstürmenden Ansprüche in Worte gefasst. Wann hat zuletzt ein deutscher Kinderurologe seine Ambitionen so geschickt theatralisch, programmatisch und visionär zum Besten gegeben? Vom Erfinder der Paediatric Urology, Sir David Innes Williams, weiß ich, dass es in den Hochzeiten der deutschen Kinderurologie einem Staatsbesuch gleichkam, wenn sein kontinentales Pendant, Rudolf Hohenfellner, nach London kam. Der ,große alte Mann" aus Mainz muß tief traurig sein, wenn er jetzt den Bildersturm seiner Kathedrale erlebt und Kirchlein um Kirchlein verlorenzugehen droht; hat man ihm doch noch nie irgendetwas streitig zu machen gewagt. Der Kern seiner Autorität, schwärmen die pädiatrischen Zeitgenossen, bestand darin, jederzeit über alle in seiner Klinik befindlichen Kinder bis ins Detail Bescheid gewusst und nie eine Röntgenschau oder Visite ausgelassen zu haben.

Mit ähnlicher Hochachtung beschreiben Augenzeugen die kunsthandwerkliche, fast liebevolle Sorgfalt und Ausdauer von Karl Michael Schrott bei der Rekonstruktion von Blasenekstrophikern. Dass selbst im allwissenden Internet von Alfred Sigel nur wenige Hinweise auf sein Standardwerk zu finden sind und noch nicht einmal ein läppischer Wikipedia-Eintrag existiert, ist beschämend für einen deutschen Gelehrten, der immerhin die Größe hatte, eigene Glaubenssätze zu revidieren. Wenn wir so mit unseren Vordenkern umgehen, entledigen wir uns freiwillig unserer Fundamente und bieten offene Flanken in der Verteidigung der Gegenwart: Nur den Geschichtslosen und Gleichgültigen kann man Dinge wegnehmen.

\section{Das Herzstück der Urologie}

Dass sich klinisch wie akademisch wissenschaftlich exzellente Kinderurologen eher niederlassen als einen Lehrstuhl zu übernehmen, oder Universitäten unwürdig ausgestatteten und klinisch überlasteten Professoren aufgrund nicht erreichter Publikationsvorgaben mit dem Entzug des Titels drohen, ist bedenklich. Auch die kalte Übernahme kinderurologischer Bestände durch den hinterbliebenen Chirurgen bei Lehrstuhlwechsel und die leidenschaftslose $\mathrm{Ab}$ schaffung der „unrentablen“ Urodynamik durch im wahrsten Sinne des Wortes einfältige Erwachsenenurologen, sind fragwürdige Vorgänge.

In einem Versuch, die Bedeutung der Kinderurologie in urologischen Händen zu demonstrieren, war es bei Übernahme der Chefredaktion ein vordringlicher Wunsch von Herrn Gross und mir, eine ganze Ausgabe von URO-NEWS diesem Herzstück der Urologie zu widmen. Erfreulicherweise ist es uns gelungen, mit Annette Schröder und Claudia Neissner sowie den Herren Wolfgang H. Rösch, Rolf Beetz, Stefan Conrad, Peter C. Rubenwolf und Florian Wimpissinger versierte Experten auf dem jeweils behandeltem Gebiet als Autoren zu gewinnen.

So lasset die Kindlein zu uns kommen!

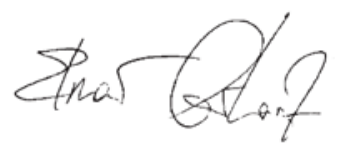

